\title{
Studies on Removal of Ni (II) Ions in Aqueous Solutions with Two Natural Wastes
}

\author{
Dr. P.V. Hemalatha \\ SG Lecturer (Redeployed), D.S. Gov't degree college (W), Ongole \\ Prof. P.V.V. Prasada Rao
}

Dept of Environmental Sciences, Andhra University, Visakhapatnam

\begin{abstract}
This article reports, the removal of Ni (II) on Papayya Seed Powder (PSP) and Sweet lime Peelings Powder $(S L P)$ as a function of pertinent variables. Adsorption kinetics data reveal the applicability Of Lagergren equation for adsorption on PSP and SLP. Experimentally measured values have been found to follow Langmuir adsorption isotherm. With these prelude studies an attempt has been made to investigate the effectiveness of low cost agro based dissipate materials in removing heavy metals. It is found that adsorption potential varies with $\mathrm{pH}$, initial concentration, contact time and adsorbent dose. Out of two low cost adsorbents used in this study Papaya Seed Powder (PSP) is found to possess greater adsorption efficiency of Ni (II) ions than SLP under nearly identical experimental conditions.
\end{abstract}

\section{INTRODUCTION}

Water is undoubtedly the most precious natural resource that exists on our planet. It is essential and pivotal for everything on our planet to grow and prosper. But Water pollution has become a threat not only to aquatic flora and fauna but also to human population causing health hazards. Heavy metals presence in water is considered to be most dangerous even at trace concentrations. Nickel being an important toxic metal finds its way to the water bodies through polluted water from refineries of silver metal, electroplating industries and storage battery industries (Kadirvelu, 2003). The nickel salts are known to be acutely and chronically toxic to human. Acute poisoning of $\mathrm{Ni}$ (II) causes headache, dizziness, nausea, and tightness of the chest, chest pain and shortness of breath, dry cough, cyanosis, and extreme weakness (Parker, 1980). At higher concentrations it is a potent carcinogen and causes cancer of lungs, nose and bone. Nickel carbonyl $\left[\mathrm{Ni}(\mathrm{Co})_{4}\right]$ has been estimated as lethal in humans at atmospheric exposure of $30 \mathrm{ppm}$ for $30 \mathrm{~min}$ (Namasivayam and Ranganathan, 1994). The toxic nature in fish, crops and algae was also reported (David, 1977). Prenatal toxicity on female rats when exposed to nickel chloride was also reported. (Kate Smith et al., 1993).

The appreciation of adsorption for the process of heavy metal removal at trace level has been constantly encouraged over other processes because of its cheapness and high quality treated effluents it produced. A huge number of low cost adsorbents have been tried by several scientists, such as coconut shell (Muthukumaran et al., 1995), bagasse (chand et al., 1994), saw dust (khaagesan et al., 1995), used waste tea leaves (Singh et al., 1993), wood barks (Ansari et al., 2000), etc.

\section{ADSORBENTS}

In the present study two adsorbents were employed to find out their utility for the removal of heavy metal ions of Ni (II) from aqueous solutions and they are papaya seeds and sweet lime peelings.

\subsection{Papaya Seed Powder (PSP)}

Papaya is a luscious and nutritious fruit that can easily grow widely in most areas of the tropics in most types of soil with tolerable pH level. Papaya seeds were either black or gray in color, fruit which is used for various medicinal purposes is widely irrigated in the agricultural fields. They were collected in bulk from fruit shops at Ongole, A.P. They were cleaned thoroughly with distilled water and soaked for $24 \mathrm{hrs}$ and again washed with distilled water and dried in sun light. The dehydrated papaya seeds were powdered by mechanical means and are screened for particle sizes of $0.6 \mathrm{~mm}, 0.8$ $\mathrm{mm}$ and $1.7 \mathrm{~mm}$. 


\subsection{Sweet Lime Peelings Powder (SLP)}

Sweet Lime (Citrus limettoides Tan. or C. lumia Risso et Poit), is called the limettier in French, limadulce in spanish; mitha limbu, mitha nimbu or mitha nebu, in India (mitha meaning sweet), quit giddy in Vietnam; limun helou or succari in Egypt; laymu-helo in Syria and Palestine. In certain areas, is referred to as "sweet lime". The origin of sweet lime is not known but it is thought to be a hybrid in Mexican-type and a sweet lemon or sweet citron. Mediterranean botanists referred it as an Indian native. In India sweet lime is grown from cuttings. Peelings of sweet lime were collected in bulk from juice shops at Ongole, A.P, and are made into small pieces, cleaned well and soaked in distilled water for 24 hours and washed with distilled water and dried under sun light and the material was pulverized using mechanical method and sieved to different particle sizes.

Particle size of $0.6 \mathrm{~mm}$ was used for both Papaya Seed Powder and Sweet Lime Peelings Powder characterization as its efficiency of metal up take is more.

All the chemicals used were of analytical reagent grade. Double distilled water was used in the preparation of solutions. All $\mathrm{pH}$ measurements were made by Elico $\mathrm{pH}$ meter, agitation of solutions were done in NeoLab Orbit shaker and colorimetric estimations were carried out in UV-Visible spectrophotometer (Type 118, Chemito).

\section{Preparation of Metal ion Solution}

\subsection{Nickel Ammonium Sulphate Solutions}

Pure Nickel ammonium sulphate was used to prepare nickel (II) solution. A stock solution of 1000 $\mathrm{mg} / \mathrm{l}$ of $\mathrm{Ni}$ (II) was prepared by dissolving $6.7280 \mathrm{~g}$ of nickel ammonium sulphate in $5 \mathrm{ml}$ of $1 \%$ $\mathrm{HNO}_{3}$ solution to prevent hydrolysis and diluted with distilled water and made up to $1000 \mathrm{ml}$.

\subsection{Analysis of Nickel (II) (Stewart, 1974)}

Nickel (II) was estimated using a UV-Visible spectrophoto meter (Chemito) by using dimethylglyoxime (DMG). To a series of $\mathrm{Ni}$ (II) standard solutions containing less than $100 \mathrm{mg} / \mathrm{l}$ of $\mathrm{Ni}$ (II) concentration, $2 \mathrm{ml}$ of 20\% (W/V) solution of Sodium Tartrate, $10 \mathrm{ml}$ of $4 \%$ (W/V) solution of Potassium Persulphate, $2.5 \mathrm{ml}$ of $5 \mathrm{M}$ sodium hydroxide solution and $15 \mathrm{ml}$ solution of $(1+30) \mathrm{Hcl}$ were added and this mixture was mixed with $0.6 \mathrm{ml}$ of $1 \%$ DMG solution. The contents were made up to $50 \mathrm{ml}$ with distilled water and after 30 minutes the absorbance was measured at $465 \mathrm{~nm}$ against a reagent blank. A calibration graph with absorbance vs concentrations of $\mathrm{Ni}$ (II) solution was prepared. The amount of $\mathrm{Ni}$ (II) in the sample was obtained from the calibration plot.

\subsection{Batch Mode Method}

Entire experiments were carried out in batch mode by taking $50 \mathrm{ml}$ of respective metal ion solution (simulated sample) and known amount of the adsorbent in lid conical flasks of $100 \mathrm{ml}$ capacity. The flasks were agitated at $160 \mathrm{rpm}$ for predetermined time intervals using a mechanical shaker at room temperature $\left(27^{\circ} \mathrm{c}\right)$. Effects of $\mathrm{pH}$, agitation time, initial metal ion concentration and amount of adsorbent were studied on the removal of metal ions. Also Control experiments were carried out without adsorbent to give correction for metal ion adsorption on the walls of the container. A very negligible adsorption of metal ion is found on the walls of the container.

\section{RESUlt \& DisCuSSION}

\subsection{Effect of $\mathrm{pH}$}

The $\mathrm{pH}$ is one of the most important factor controlling the uptake of ions of metals from aqueous solutions by adsorbents.

Figure -1 shows the effect of $\mathrm{pH}$ in the removal of Ni (II) ions by Papaya Seed Powder and Sweet Lime Peelings Powder. Maximum percent removal of 95.96\% was achieved at $\mathrm{pH} 3.0$ for PSP and 92.56\% were observed at $\mathrm{pH} 4.0$ for SLP. At $\mathrm{pH}>6$ precipitation started in both the cases in the absence of adsorbent. So the adsorption of Ni (II) ion is reported to be highly $\mathrm{pH}$ dependent. 


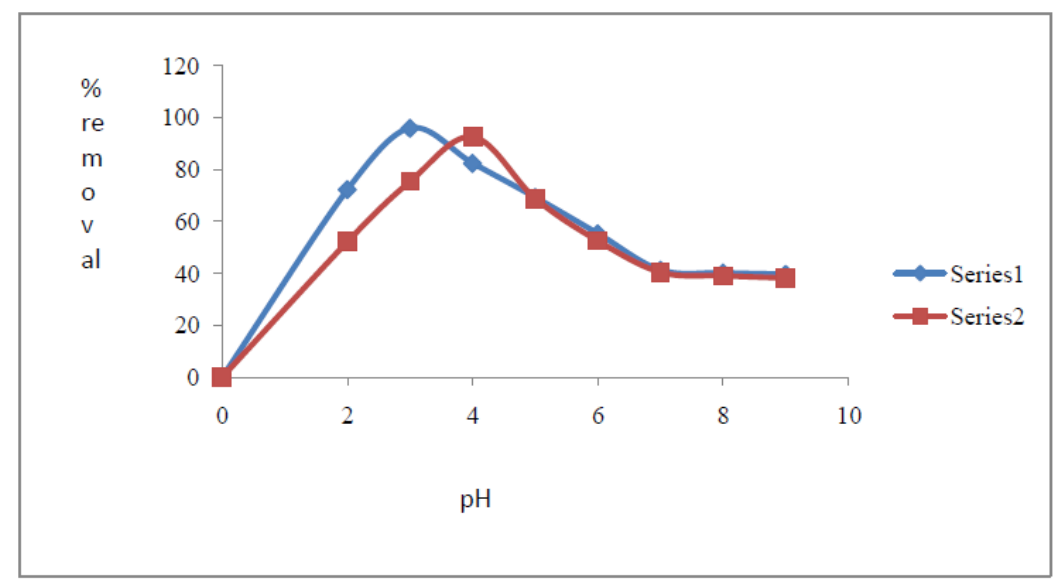

Figure1. Effect of pH (Series1-PSP,Series 2-SLP)

\subsection{Effect of Initial Concentration and Contact Time}

From Figure -2 and Table $1 \& 2$ we can compare the \% removal of $\mathrm{Ni}$ (II) ions in aqueous solutions by increasing initial concentration and contact time using Papayya Seed Powder and Sweet Lime Peelings Powder at $125 \mathrm{mg} / 50 \mathrm{ml}$ of adsorbent doses and 90 minutes contact time. In Figure-2, series1, 2, 3 and series-4, 5, 6 indicates $50 \mathrm{mg} / 1,75 \mathrm{mg} / 1$ and100mg/l initial concentrations of Papayya Seed Powder and Sweet Lime Peelings Powder respectively.PSP and SLP gave 95.96\% and 92.96\% removal percentage respectively for $\mathrm{Ni}(\mathrm{II})$ initial concentration of $50 \mathrm{mg} / \mathrm{l}$ from which the percent removal gradually decreases with increasing concentration, because at lower initial concentrations, sufficient sites are available for adsorption of metal ions. Therefore the fractional adsorption is independent of initial concentration. However, at higher concentrations the number of metal ion is relatively higher compared to availability of adsorption sites. Hence, the \% removal of metal ion depends on initial concentration. The solutions were equilibrated for 120 minutes where maximum removal and equilibrium attained at 90 minutes irrespective of initial concentration. The rate of uptake was rapid in the beginning and became slow in the later stages and reached saturation at 90 minutes. This is due to the fact that the metal ion occupied the sites in a random manner because of maximum availability of sites. As the time passed, the active sites were blocked and hence the rate was slowed. The slight difference in the percent removal of Ni (II) ions in PSP and SLP may be due to the difference in Chemical affinity on the surface of adsorbent.

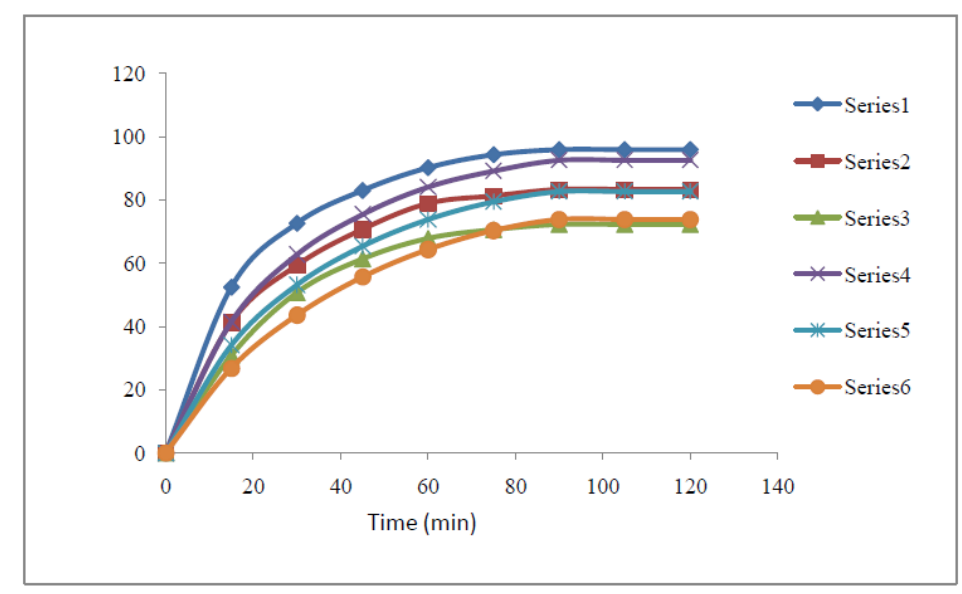

Figure2. Effect of Initial Concentration And Contact Time (Series1,2,3-PSP \& Series 4,5,6-SLP)

Table1. Series 1, 2, 3-PSP

\begin{tabular}{|l|l|l|l|l|l|l|l|l|l|}
\hline \multirow{2}{*}{$\begin{array}{l}\text { Ni(II) } \\
\mathrm{mg} / \mathrm{l}\end{array}$} & Agitation time in (min) & 15 & 30 & 45 & 60 & 75 & 90 & 105 & 120 \\
\cline { 2 - 11 } & \%Removal & 52.42 & 72.65 & 83.04 & 90.25 & 94.35 & 95.96 & 95.96 & 95.96 \\
\cline { 2 - 11 } 50 & $\begin{array}{l}\text { Amount of Ni(II) adsorbed } \\
(\mathrm{mg} / \mathrm{g})\end{array}$ & 10.48 & 14.13 & 16.60 & 18.05 & 18.87 & 19.19 & 19.19 & 19.19 \\
\cline { 2 - 11 } & $\mathrm{q}_{\mathrm{e}-\mathrm{q}}$ & 8.71 & 5.06 & 2.59 & 1.14 & 0.32 & - & - & - \\
\hline
\end{tabular}


Dr.P.V.Hemalatha \& Prof.P.V.V.Prasada Rao

\begin{tabular}{|c|l|l|l|l|l|l|l|l|l|}
\hline \hline \multirow{3}{*}{75} & \%Removal & 41.25 & 59.29 & 70.68 & 78.85 & 81.25 & 83.28 & 83.28 & 83.28 \\
\cline { 2 - 10 } & $\begin{array}{l}\text { Amount of Ni(II) adsorbed q } \\
(\mathrm{mg} / \mathrm{g})\end{array}$ & 12.37 & 17.78 & 21.20 & 23.65 & 24.37 & 24.98 & 24.98 & 24.98 \\
\cline { 2 - 10 } & $\mathrm{q}_{\mathrm{e}} \mathrm{q}$ & 12.61 & 7.20 & 3.78 & 1.33 & 0.61 & - & - & - \\
\hline \multirow{3}{*}{100} & \%Removal & 30.80 & 50.71 & 61.36 & 67.87 & 70.64 & 72.28 & 72.28 & 72.28 \\
\cline { 2 - 10 } & $\begin{array}{l}\text { Amount of Ni(II) adsorbed q } \\
(\mathrm{mg} / \mathrm{g})\end{array}$ & 12.32 & 20.28 & 24.54 & 27.14 & 28.25 & 28.91 & 28.91 & 28.91 \\
\cline { 2 - 9 } & $\mathrm{q}_{\mathrm{e}}-\mathrm{q}$ & 16.59 & 8.63 & 4.37 & 1.77 & 0.66 & - & - & - \\
\hline
\end{tabular}

qe for $50 \mathrm{mg} / \mathrm{L}=19.19 \mathrm{mg} / \mathrm{g}, 75 \mathrm{mg} / \mathrm{L}=24.98 \mathrm{mg} / \mathrm{g}, 100 \mathrm{mg} / \mathrm{L}=28.91 \mathrm{mg} / \mathrm{g}$

Table2. Series 4, 5, 6-SLP

\begin{tabular}{|c|c|c|c|c|c|c|c|c|c|}
\hline \multirow{2}{*}{$\begin{array}{l}\mathrm{Ni}(\mathrm{II}) \\
\mathrm{mg} / \mathrm{l}\end{array}$} & \multirow[b]{2}{*}{ Agitation time min } & \multirow[b]{2}{*}{15} & \multirow[b]{2}{*}{30} & \multirow[b]{2}{*}{45} & \multirow[b]{2}{*}{60} & \multirow[b]{2}{*}{75} & \multirow[b]{2}{*}{90} & \multirow[b]{2}{*}{105} & \multirow[b]{2}{*}{120} \\
\hline & & & & & & & & & \\
\hline \multirow{3}{*}{50} & \%Removal & 41.44 & 62.70 & 75.40 & 84.08 & 89.16 & 92.56 & 92.56 & 92.56 \\
\hline & $\begin{array}{l}\text { Amount of } \mathrm{Ni}(\mathrm{II}) \\
\text { adsorbed } \mathrm{q}(\mathrm{mg} / \mathrm{g})\end{array}$ & 8.28 & 12.54 & 15.08 & 16.81 & 17.83 & 18.51 & 18.51 & 18.51 \\
\hline & $\mathrm{q}_{\mathrm{e}}-\mathrm{q}$ & 10.22 & 5.97 & 3.43 & 1.70 & 0.68 & - & - & - \\
\hline \multirow{3}{*}{75} & \%Removal & 34.04 & 53.13 & 65.36 & 73.84 & 79.44 & 82.66 & 82.66 & 82.66 \\
\hline & $\begin{array}{l}\text { Amount of } \mathrm{Ni}(\mathrm{II}) \\
\text { adsorbed } \mathrm{q}(\mathrm{mg} / \mathrm{g})\end{array}$ & 10.21 & 15.94 & 19.60 & 22.15 & 23.83 & 24.80 & 24.80 & 24.80 \\
\hline & $\mathrm{q}_{\mathrm{e}}-\mathrm{q}$ & 14.59 & 8.86 & 5.20 & 2.65 & 0.97 & - & - & - \\
\hline \multirow{3}{*}{100} & $\%$ Removal & 26.77 & 43.58 & 55.62 & 64.33 & 70.32 & 73.82 & 73.82 & 73.82 \\
\hline & $\begin{array}{l}\text { Amount of } \mathrm{Ni}(\mathrm{II}) \\
\text { adsorbed } \mathrm{q}(\mathrm{mg} / \mathrm{g})\end{array}$ & 10.70 & 17.43 & 22.24 & 25.73 & 28.12 & 29.52 & 29.52 & 29.52 \\
\hline & $\mathrm{q}_{\mathrm{e}}-\mathrm{q}$ & 18.82 & 12.09 & 7.28 & 3.79 & 1.40 & - & - & - \\
\hline
\end{tabular}

qe for $50 \mathrm{mg} / \mathrm{L}=18.51 \mathrm{mg} / \mathrm{g}, 75 \mathrm{mg} / \mathrm{L}=24.80 \mathrm{mg} / \mathrm{g}, 100 \mathrm{mg} / \mathrm{L}=29.52 \mathrm{mg} / \mathrm{g}$

\section{EFFECT OF AdSORbENT DOSE}

From Figure-3, in Table 3 and Table4 it is observed that the adsorptive behavior of Ni (II) ions on Papaya Seed Powder and Sweet Lime Peelings Powder increased with increasing adsorbent dosage. It is observed that there is increase in \% removal of $\mathrm{Ni}$ (II) ions with increasing dosage of PSP, i.e. from $31.18-100 \%$ at 25 to $175 \mathrm{gm} / 50 \mathrm{ml}$ adsorbent dosage. Also \% removal with SLP increased from $28.70-99.07 \%$ for $\mathrm{Ni}$ (11) ions at $25-175 \mathrm{gm} / 50 \mathrm{ml}$ adsorbent dosage. It is apparent that there is gradual increase in percent removal with increase in adsorbent dosage in both the cases. It is attributed to the greater availability of the active sites or surface area at higher doses of the adsorbent.

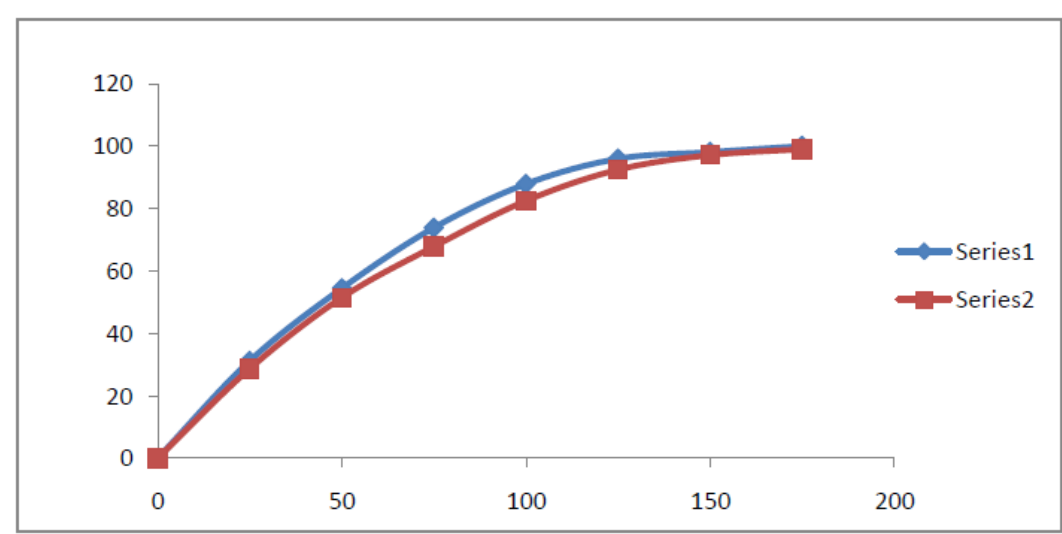

Figure3. Effect of Adsorbent Dosage (Series1-PSP \& Series2-SLP)

Table3. PSP Adsorbent Dose

\begin{tabular}{|l|l|l|l|}
\hline Adsorbent dose $(\mathrm{g} / 50 \mathrm{ml})$ & \% Removal & Equilibrium concentration Ce $(\mathrm{mg} / \mathrm{l})$ & Amount adsorbed mg/g \\
\hline 25 & 31.18 & 29.89 & 40.22 \\
\hline 50 & 54.42 & 22.79 & 27.21 \\
\hline 75 & 73.82 & 13.09 & 24.60 \\
\hline 100 & 89.84 & 5.08 & 22.46 \\
\hline 125 & 95.92 & 2.04 & 19.18 \\
\hline 150 & 98.08 & 0.96 & 16.34 \\
\hline 175 & 100.00 & 0.00 & 14.28 \\
\hline
\end{tabular}


Table4. SLP Adsorbent Dose

\begin{tabular}{|l|l|l|l|}
\hline Adsorbent dose $\mathrm{mg} / 50 \mathrm{ml}$ & \% Removal & Equilibrium Concentration Ce(mg/l) & Amount adsorbed (mg/g) \\
\hline 25 & 28.70 & 35.64 & 28.72 \\
\hline 50 & 51.48 & 24.26 & 25.74 \\
\hline 75 & 67.84 & 16.08 & 22.61 \\
\hline 100 & 82.50 & 8.75 & 20.62 \\
\hline 125 & 92.48 & 3.76 & 18.49 \\
\hline 150 & 97.16 & 1.42 & 16.19 \\
\hline 175 & 99.04 & 0.48 & 14.14 \\
\hline 200 & 100.00 & 0.00 & 12.50 \\
\hline
\end{tabular}

(Agitation time - 90 Initial pH - 4.0,Ni (II) - 50mg / l, Particle size 0.6mm

\section{ADSORPTION KINETICS}

Kinetics and equilibrium are the two major factors to evaluate adsorption dynamics. The mechanism involved in the metal ion removal is assumed to be basically complexation (Krishnan et al., 2002). The kinetics of metal removal can be expressed as.

$$
\mathrm{N}+\mathrm{M}=\mathrm{NM}
$$

Where $\mathrm{M}$ is the concentration of free metal ion in solution, $\mathrm{N}$ is the number of active sites present on the adsorbent. NM is the concentration of metal bound to adsorbent. Adsorption occurs only on localized sites and involves no interaction between adsorbed ions. The energy of adsorption is independent of surface coverage, maximum adsorption corresponds to a saturated monolayer of adsorbates on the adsorbent surface. The process of metal uptake on Papayya Seed Powder and Sweet Lime Peelings Powder is governed by first order and is Chemical in nature, i.e. Chemisorption. The adsorption kinetics of Ni (II) ions adsorption on Papayya Seed Powder and Sweet Lime Peelings Powder follows Lagergren equation.

$$
\log \left(q_{e}-q\right)=\log q_{e}-\frac{K_{a d}}{2.303} t
$$

Where $\mathrm{K}_{\mathrm{ad}}$ is the rate constant of adsorption (min. ${ }^{-1}$ ), $\mathrm{q}$ and $\mathrm{q}_{\mathrm{e}}$ is the amount of metal ions adsorbed $(\mathrm{mg} / \mathrm{g})$ at time $\mathrm{t}$ and equilibrium time respectively, linear plots of $\log \left(\mathrm{q}_{\mathrm{e}}-\mathrm{q}\right)$ vs $\mathrm{t}$ i.e. Figure- 4 and Figure-4s show the applicability of above equation for Papayya Seed Powder and Sweet Lime Peelings Powder. The $\mathrm{K}_{\mathrm{ad}}$ values of Ni (II) ion of various concentrations and adsorbent dose of 125 $\mathrm{mg}$. / $50 \mathrm{ml}$. of PSP and SLP were calculated from the slope of linear plots. The $\mathrm{K}_{\mathrm{ad}}$ values are comparable with recently reported values of $\mathrm{Ni}$ (II) ions in the literature.

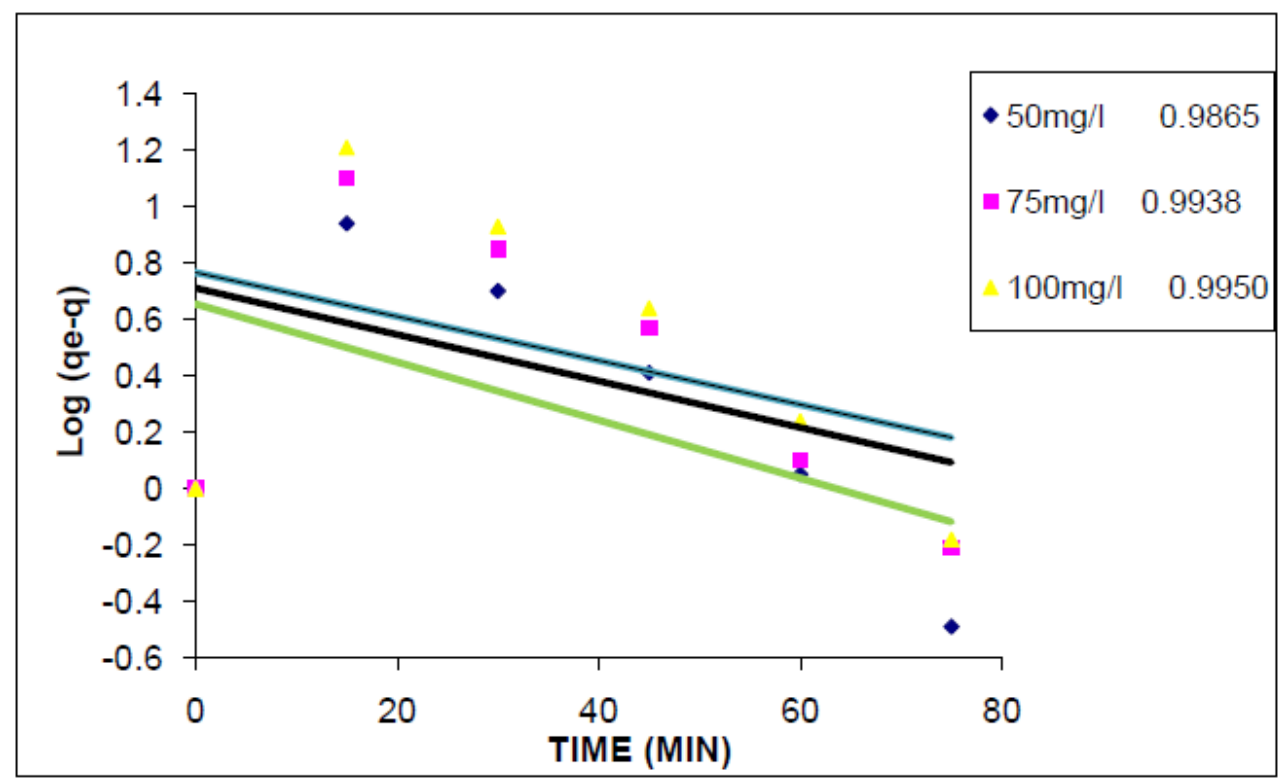

Figure4. Lagergren Rate Constant-PSP 


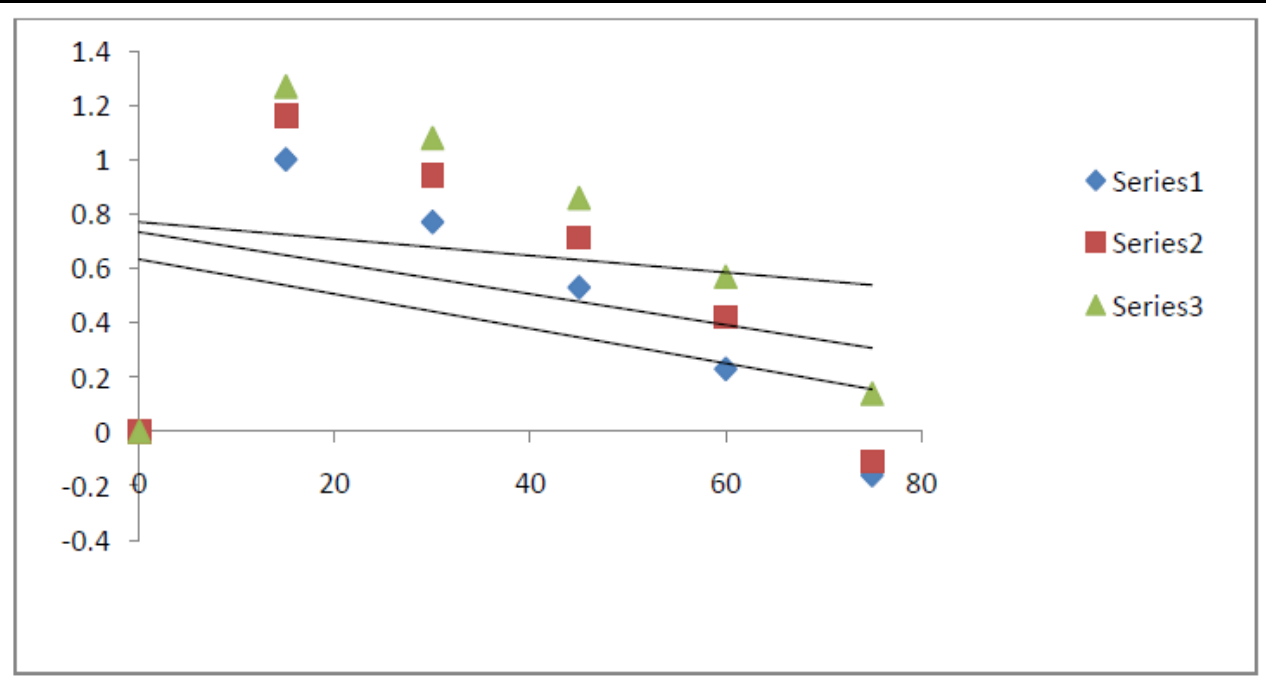

Figure4s. Lagergren Rate Constant-SLP

\section{FreUndLich EQuation}

The freundlich expression is an empirical equation based on adsorption of heterogeneous surface. It is commonly represented as (Freundlich, 1939)

$$
\log x / m=\log k_{f}+\frac{1}{n} \log C e
$$

Where $(\mathrm{X} / \mathrm{m})$ is the amount adsorbed $(\mathrm{mg} / \mathrm{l})$, Ce is the equilibrium concentration $(\mathrm{mg} / \mathrm{l})$ and $\mathrm{K}_{\mathrm{f}}$ and $\mathrm{n}$ are Freundlich constants, where $\mathrm{K}_{\mathrm{f}}$ indicates the adsorbent capacity and $\mathrm{n}$ indicates the favorability of adsorption. Linear plots of $\log (\mathrm{x} / \mathrm{m})$ vs $\log \mathrm{Ce}$ in Figure-5 and Figure-5s shows that the adsorption follows Freundlich Isotherm. In case of PSP $\mathrm{K}_{\mathrm{f}}$ and $\mathrm{n}$ are 28.13 and 3.43 respectively and for SLP $\mathrm{K}_{\mathrm{f}}$ and $n$ are 23.92 and 2.24 respectively. If the value of $n$ lie between 1 and 10 indicates favorable adsorption also these $\mathrm{K}_{\mathrm{f}}$ values are comparable to literature with silk cotton hull activated carbon 39.8(Shanmugavalli.M.2006).

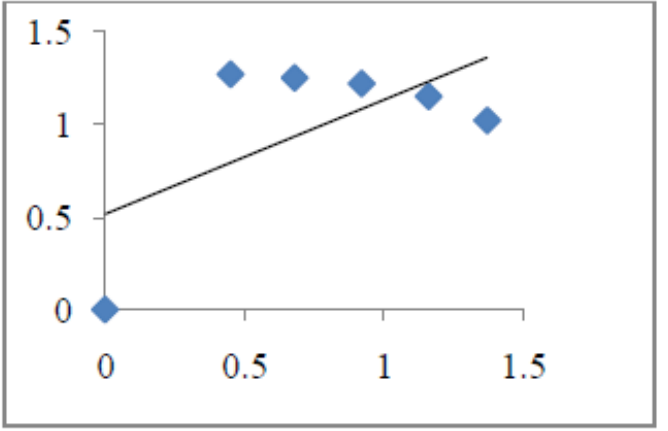

Figure5. Freundlich Isotherm $-P S P$

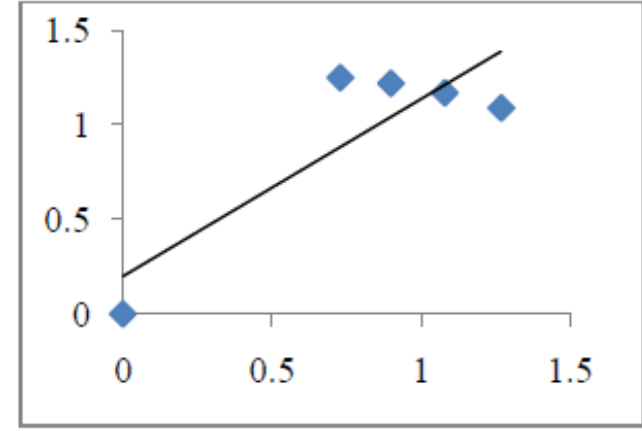

Figure5s. Freundlich Isotherm -SLP

\section{LANGMUir EQUation}

The most widely used isotherm for equilibrium data of dilute solutions is the Langmuir equation. It may be represented as (Langmuir, 1918)

$$
\frac{C e}{q e}=\frac{1}{Q_{0} b}+\frac{C e}{Q_{0}}
$$

Where qe is the amount of $\mathrm{Ni}$ (II) adsorbed at equilibrium. This is applicable to homogeneous adsorption and also obeys Henry's law at low concentrations. The Linear plot of Ce/qe vs. Ce in Figure-6 and Figure-6s show that the adsorption obeys Langmuir model. Here $\mathrm{Q}_{0}$ and $\mathrm{b}$ were determined from the slope and intercept of the Langmuir plot. $\mathrm{Q}_{0}$ for Papaya Seed Powder and Sweet Lime Peelings Powder were 30.58 and 29.14 and b for Papaya Seed Powder and Sweet Lime Peelings Powder were 0.5092 and 0.4789 respectively. 


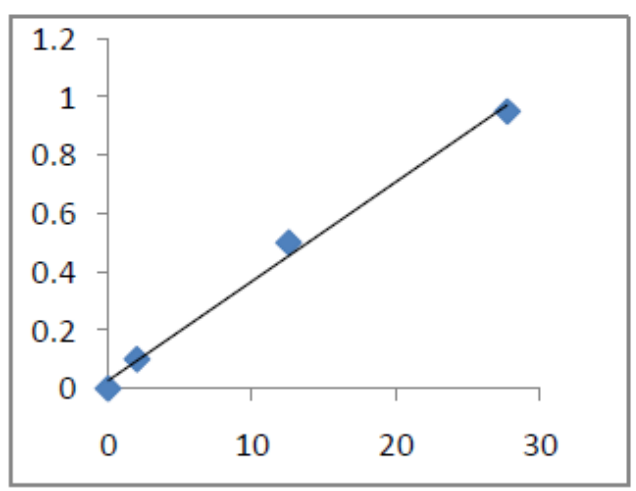

Figure6. Langmuir Isotherm -PSP

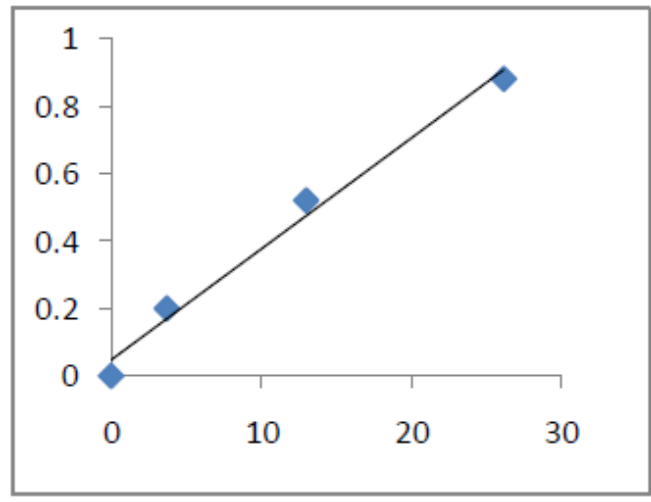

Figure6s. Langmuir Isotherm -SLP

On the basis of regression analysis of the experimental data on the adsorptive behavior of $\mathrm{Ni}$ (II) on PSP and SLP, it may be inferred that the adsorption behavior of $\mathrm{Ni}$ (II) is in good concurrence with Langmuir model.

This can be attributed to the formation of mono layer coverage on the surface of Papaya Seed Powder and Sweet Lime Peelings Powder with minimal interaction among molecules of substrate, immobile and localized adsorption and all sites having equal adsorption energies. The essential characteristics of Langmuir isotherm can be described by a separation factor of equilibrium constant $R_{L}$, which is given as

$$
R_{L}=\frac{1}{1+b c_{i}}
$$

Where $\mathrm{C}_{\mathrm{i}}$ is the initial concentration $(\mathrm{mg} / \mathrm{l})$ and $\mathrm{b}$ is the Langmuir constant.

The value of $\mathrm{R}_{\mathrm{L}}$ indicates the nature of isotherm as presented in format below.

Equilibrium Parameter and Nature of Isotherm

\begin{tabular}{|l|l|}
\hline \multicolumn{1}{|c|}{$\mathbf{R}_{\mathbf{L}}$} & Type of Isotherm \\
\hline $\mathrm{R}_{\mathrm{L}}>1$ & Unfavorable \\
\hline $\mathrm{R}_{\mathrm{L}}=1$ & Linear \\
\hline $0<\mathrm{R}_{\mathrm{L}}<1$ & Favorable \\
\hline $\mathrm{R}_{\mathrm{L}}=0$ & Irreversible \\
\hline
\end{tabular}

The $\mathrm{R}_{\mathrm{L}}$ values indicate the type of isotherm. The $\mathrm{R}_{\mathrm{L}}$ values were set up between zero and one (Hall, 1966) which were also proved to subsist in Papayya Seed Powder and Sweet Lime Peelings Powder for $\mathrm{Ni}$ (II) ions and so they exhibit a favorable adsorption.

\section{Conclusion}

1. Aim of this research work is to develop inexpensive and effective heavy metal ion removal methods to compensate existing commercial and expensive methods.

2. The availability of material source is bounteous.

3. The adsorption is $\mathrm{p}^{\mathrm{H}}$ dependent and hence maximum adsorption occurs at a $\mathrm{p}^{\mathrm{H}}$ of 3.0 and 4.0 for PSP and SLP respectively i.e. uptake of $\mathrm{Ni}$ (II) is found to be maximum at lower $\mathrm{p}^{\mathrm{H}}$.

4. PSP showed $95.96 \%$ and SLP showed $92.56 \%$ adsorptive removal of $\mathrm{Ni}$ (II) under the conditions of $125 \mathrm{mg} / 50 \mathrm{ml}$ adsorbent dose with a 90 minute contact time and a particle size of $0.6 \mathrm{~mm}$.

5. The Langmuir model was found to be in good agreement with experimental data on the adsorptive behavior of Ni (II) on PSP and SLP.

6. The adsorption follows first order kinetics. Lagergren kinetic model had been applicable for PSP and SLP on Ni (II) adsorption.

7. Out of two low cost adsorbents used in this study, Papayya Seed Powder is found to exhibit greater adsorption efficiency of Ni (II) ions than Sweet Lime Peelings Powder under identical experimental conditions. 


\section{REFERENCES}

[1] Amalraj.S., 2004 Adsorption behavior of nickel on activated carbon; IJEP 24 (7): 530-533.

[2] Ansari, M.H., et al. 2000. Neem (Azadiracta indica) bark for removal of mercury from water. J. IAEM. 27: 133-137.

[3] Chand, S., V.K. Agarwal and Pavan kumar. 1994. Removal of hexavalent chromium from wastewater by adsorption. Indian J. Env.

[4] David.P, 1977 Trace Element Contamination of the Environment, Elesevier, Amsterdam, pp 143.

[5] Freundlich,H .1906. Adsorption in solution., J. Am. Chem. Soc., 40:1361-1368

[6] Hall, K.R., et al, 1966. Ind. Eng. Chem. Fund., 5: 212 - 219.

[7] Kadirvelu K. and V. Subburam; 2003. Activated carbon prepared from biomass as an adsorbent for the removal of Ni (II) from Aqueous solution; IJEP 23 (12): 1343-1350

[8] Kate Smith M, Emma Lou George, Judith A, Stober, Huiling A. Feng, and Gary L. Kimmel;1993. Perinatal Toxicity Associated with Nickel Chloride Exposure, Environmental Research 61, 200-211 .

[9] Khaagesan, P., P. Srinivas rao and p. Shivraj. 1991. Colour removal studies on textile dye waste using activated carbons and bleaching powder. J.IPHE. (2): 20-27.

[10] Krishnan, K.A. and T.S. Anirodhan, (2002). Removal of Mercury (II) from aqueous solutions and Chlor-alkali industry effluent by steam activated and sulphurised activated Carbons prepared from bagasse pith: Kinetics and equilibrium studies. J. Hazardous Materials, B. 92: 161-183

[11] Langmuir,I 1918. The adsorption of gases on plane surfaces of glass,mica and platinum; Am.Che.Soci.,40: 1361.

[12] Muthukumaran,N.,N. Balasubramanian and T.V. Ramakrishnan. 1995. Removal and recovery of lead and cadmium from plating wastes. J.IAEM. 22: 136-141.

[13] Namasivayam C. and K. Ranganathan, 1994. Recycling of waste Fe (III). /Cr (III) hydroxide for the removal of Nickel from waste water. Adsorption and Eq1uilibrium Studies, Waste Management 14, 709-716.

[14] Parker. P, 1980. Encyclopedia of Environmental Sciences ( $2^{\text {nd }}$ edn), Mc Graw Hill, New York, pp. 354-358.

[15] Periasamy, K.,K. srinivasan and P.K. murugan. 1991. Studies on chromium (VI) removal by activated groundnut husk carbon. Indian J. Env. Health. 33(4):433-439.

[16] Periasamy. K. and C. Namasivayam, 1995. Removal of Ni (II) from aqueous solution and nickel plating industry waste water using an agricultural waste: Peanut hull, Waste Management, 15: 63-68.

[17] Shanmugavalli.M,Madhavakrishnan.S,Kadirvelu.K,Sathishkumar Mohanraj.r and Pattabhi.S; 2006. Removal of Ni (II) from aqueous solution using silk cotton hull activated carbon; IJEP 26(1):47-53.

[18] Singh, D.K., D.P. Tiwari and D.N. Saksena. 1993. Removal of lead from aqueous solutions by chemically treated used tea leaves. Indian J. Env. Health. 35(3): 169-177.

[19] Tribal, R.E 1980. Mass transfers operations (3rd edn.) Mc. Graw, New York. 